\title{
PARENTAL AGE AND HERITABILITY OF STERNOPLEURAL CHAETA NUMBER IN DROSOPHILA MELANOGASTER
}

\author{
J. A. BEARDMORE, ${ }^{1}$ F. LINTS ${ }^{1}$ and A. L.j F. AL-BALDAWI ${ }^{2}$ \\ Department of Genetics, University College of Swansea, and Laboratoire de Génétique, \\ Université de Louvain, Belgium
}

Received 1.v.74

\section{Summary}

Evidence is presented that the heritability of sternopleural chaeta number in Drosophila melanogaster is influenced by the age of the parents such that estimates based upon parents 14 days and older are significantly higher than those from 3 -day-old parents. The increase is generally between 60 and 100 per cent when parents with mean ages of 3 days and 21 or 28 days are compared.

The age-effect on $h^{2}$ is more marked with age of mother, but there is a male effect when all comparisons are made between young mothers. The increase is found with estimates of $h^{2}$ based both on offspring mid-parent regression and on half sib analyses, but may be more marked with the former. The increase in $h^{2}$ is significantly less when females first mated when young are used than when females kept virgin until just prior to the test of heritability are used as old mothers.

Some possible causes for these effects of parental age upon heritability and the expression of quantitative characters are discussed.

\section{InTRODUCTION}

THE heritability of a quantitative trait (Lush, 1941) is defined as the ratio of the additive genetic variance to the total phenotypic variance, $V_{A} / V_{P}$ or, from a more practical point of view, as the regression of breeding value on phenotypic value, $h^{2}=b_{A P}$ (Falconer, 1960). It follows that heritability depends on both gene and genotype frequencies of the population in which it is measured and on the environment in which that population is bred.

The dependence upon gene and genotype frequencies is exemplified by the very different estimates of heritability found for the same character in different populations. For instance, the heritability of abdominal sternite bristle number in Drosophila melanogaster has been estimated to be 0.51 in a strain from West Africa (Clayton, Morris and Robertson, 1957), 0.15 in a strain from Canberra (Jones, Frankham and Sheridan, 1969), 0.40 in a Nettlebed strain (Reeve and Robertson, 1954) and 0.20-0.25 in an Oregon strain (Sheldon, 1963). Such differences may, of course, also be found when different species are compared and have indeed been reported by Tantawy, Mallah and Tewfik (1964) for wing length in D. melanogaster and D. simulans.

As heritability depends on genotype frequencies it should therefore decrease as inbreeding proceeds in a population, i.e. as the fraction of homozygous loci increases. Direct evidence of that dependence is surprisingly rare: Tantawy and Reeve (1956) found a decrease in heritability of wing length in various lines of $D$. melanogaster inbred at different rates. However, indirect evidence is provided by studies in which selection in highly inbred lines was ineffective (Rasmuson, 1952), from comparison of realised heritabilities in inbred and outbred lines (Lewis and Warwick,

1 Requests for reprints to J.A.B. or F.L.

2 Present address: College of Medicine, Baghdad University, Iraq. 
1953) and from comparison of the realised heritabilities in populations reproduced from large or small numbers of individuals (Frankham, Jones and Barker, 1968). It must, however, be stressed that experimental evidence exists which cannot easily be reconciled with such dependence. For instance it is sometimes possible to select in inbred lines, even in highly inbred lines, as shown by Kislovsky (1937) — cited by Lerner (1958) - Rasmuson (1952) and Petit (1963). However, these discrepancies do not necessarily invalidate the theory of heritability for they probably simply depend on the fact that the increase in homozygosity on inbreeding may be slower than theoretically anticipated.

Heritability also depends on the environment and changes in heritability can be produced by changes in the additive or the phenotypic variance or both of these. Lerner (1954) brings together many data showing that phenotypic variance may be strongly influenced by genetic constitution even when the genetic variance in the material being compared is the same. Several studies suggest that the total phenotypic variance varies as a function of environment (Lints, 1961 ; Taneja and Negi, 1964). However, the magnitude of these changes seems to be dependent on the trait considered and may, in certain cases, only reflect a change in the mean. It is worth noting that gene-environment interactions, which are now regarded as quite common, create an interaction variance which is, of course, part of the total phenotypic variance.

Estimates of heritability of a given trait in a given strain in different environments suggest that the additive genetic variance may also vary as a function of the environment (Tantawy, Mallah and Tewfik, 1964). The different results of selection realised on the same strain in different environments (Robertson, 1960; Tantawy, Mallah and Tewfik, 1964) point in the same direction. The work of Beardmore and Levine (1963) and Powell (1971) provides good evidence that the ecological heretogeneity of the environment exerts a considerable influence on the amount of genetic variability in populations.

Since the work of Bridges (1915, 1927) and Plough (1917), it has been known that parental age may influence genetic properties. In $D$. melanogaster Bridges and Plough demonstrated that the amount of crossing-over may change with the age of the female, and a recent study by Valentin (1973) showed an age-dependent increase in recombination in a section of the $\mathrm{X}$ chromosome and a decrease in a section of Chromosome II in Drosophila. Heuts (1956) in a study of monogenic and digenic segregation in $D$. melanogaster has shown that segregation is not random as a function of the age of the female; he also showed that the sex-ratio may vary as a function of the same factor (Heuts, 1961). The frequency of non-disjunction is strongly agedependent in the case of chromosome 21 in female gametogenesis in man (Penrose, 1965) and a similar result has been observed for the $\mathrm{X}$ chromosome in D. melanogaster (Tokunaga, 1970). Numerous other examples, especially in man, have been reviewed by Parsons (1964). The age of the male may also influence genetic variation in the offspring. Hiraizumi and Watanabe (1969), in a study of the SD element of chromosome II in D. melanogaster, have shown that the proportions of the two different sperms from heterozygous males vary as a function of age.

It is thus apparent that a number of genetic attributes of individuals may vary as a function of parental age and that population parameters such as 
environmental variance (and hence total phenotypic variance) and additive variance may vary as a function of genotype or environment.

While it is a basic assumption in population genetics that heritability is modifiable by the external environment, the effects of variation in the internal environment have remained largely unconsidered. Age represents one relevant variable and appropriate experiments could then be expected both to contribute to our present inadequate knowledge of genetic factors in ageing (Medvedev, 1971) and to indicate the extent of any age effects upon heritability with the important implications for the theory and practice of selection that their existence would have.

Preliminary experiments carried out by one of us (F.L.) had produced data strongly suggesting that the heritability of abdominal bristle number in Drosophila is influenced by parental age and the work reported in this paper represents an attempt to study the problem more intensively.

\section{MATERIALS AND METHODS}

An outbred stock of D. melanogaster of Greek origin (Votanikos) derived from flies captured in 1969, and upon which extensive selection experiments are being carried out, was used. The character whose heritability was assayed was sternopleural chaeta number (SPC), both because this is involved in many of the selection experiments and because it is a character which has been widely used in many laboratories. Cultures were grown at $25^{\circ} \mathrm{C}$ with a 16-hour light/8-hour dark cycle.

In the first experiment, each male was mated to two females about 27 hours old for 24 hours. The females were separated and put, singly, into $100 \times 25 \mathrm{~mm}$ vials to lay eggs for 45 hours (3-day progenies). The females were then removed and stored, together with the male at $18^{\circ} \mathrm{C}$ for 16 days and then again placed singly in vials for 48 hours to produce the second progeny (21-day progenies). Only those matings in which both females produced both " young" and " old" progenies are included in the analysis. Both random and assortative matings were used in separate blocks and five flies of each sex from each progeny were stored for sternopleural chaeta number.

In the later experiments only random matings were used and the flies used to produce old and young progenies were not the same. This has an obvious disadvantage but allows more precise control of environmental variables and in particular ensures that the environment of "old " and "young" progenies are similar. In order that all heritability tests in each experiment could be run at the same time, flies were taken randomly from cultures raised with constant density at $25^{\circ} \mathrm{C}$. To keep flies until they were required, they were stored at $18^{\circ} \mathrm{C}$ and matings were carried out at $25^{\circ} \mathrm{C}$. In the second experiment " old " parents were tested at 28 days of age and in the third and fourth experiments at this and at other ages.

The freezing procedure followed in blocks $\mathrm{E}$ and $\mathrm{F}$ in experiment II was to put females, inseminated when young, into empty $100 \times 25 \mathrm{~mm}$ glass vials and to place them in a deep freeze at $-10^{\circ} \mathrm{C}$ for 10 minutes. No mortality was observed and, unless remated, females did not produce fertile eggs after such treatment.

In calculating estimates of heritability the standard procedures as described by Falconer (1960) for offspring mid-parent regression and 
half-sib analysis were followed. The half-sib values given in the results are means of the sire and dam estimates. Levels of significance in tables are indicated as follows: **** $\mathrm{P}=<0.00 \mathrm{I} ; * * * \mathrm{P}=<0.002 ; * * \mathrm{P}=<0.0 \mathrm{I}$; $* \mathrm{P}=<0.05 ;^{\circ}=$ n.s.

\section{Results}

In the first experiment, estimates of heritability based upon half sibs (HS) and offspring mid-parent regression (OP) were obtained from parents with a mean age of 3 days and again when these parents had a mean age of 21 days. Two types of mating scheme-random and assortative-were used and parents were divided into three blocks dependent upon their own time of emergence from the pupa (early, mid and late). The estimates of $h^{2}$ are shown in table 1. The pattern of these estimates is such that, in general,

TABLE 1

Estimates of heritability using $O P$ and $H S$ methods, random and assortative mating, parents when young and when old and parents eclosing at different times. The number of cultures used for each estimate is indicated in brackets-experiment $I$.

\begin{tabular}{|c|c|c|c|c|c|c|c|}
\hline \multirow{3}{*}{$\begin{array}{l}\text { Type of } \\
\text { mating }\end{array}$} & \multirow{3}{*}{$\begin{array}{l}\text { Type of } \\
h^{2} \\
\text { estimate }\end{array}$} & \multicolumn{6}{|c|}{ Emergence of parents } \\
\hline & & \multicolumn{2}{|c|}{ Early } & \multicolumn{2}{|c|}{ Mid } & \multicolumn{2}{|c|}{ Late } \\
\hline & & Young & Old & Young & Old & Young & Old \\
\hline \multirow{2}{*}{$\begin{array}{l}\text { Random } \\
\text { mating }\end{array}$} & OP & 0.261 & 0.310 & 0.292 & 0.392 & 0.358 & 0.456 \\
\hline & HS & 0.403 & 0.650 & $0.443^{\prime}$ & 0.607 & 0.540 & 0.599 \\
\hline \multirow[t]{2}{*}{$\begin{array}{l}\text { Assortative } \\
\text { mating }\end{array}$} & OP & \multicolumn{2}{|c|}{$(56)^{0.422}$} & \multicolumn{2}{|c|}{ (54) } & (32) & 0.491 \\
\hline & HS & 0.702 & 0.678 & 0.842 & 0.844 & 0.405 & 0.591 \\
\hline
\end{tabular}

assortative mating estimates exceed random mating estimates, half sib values exceed off-spring mid-parent values, and old parent estimates are greater than young parent estimates.

In table 2 an analysis of variance shows that all of the main items are statistically significant. The difference between mating systems is not of course unexpected and needs no further comment. The difference of emergence time of parents led to the choice of parents in subsequent experiments being restricted to mid-emerging flies. The significant difference between OP and HS estimates is puzzling and there is no obvious explanation for it. In the later experiments differences between OP and HS estimates were also seen but were not consistently in one direction as in table I. There is an interaction between mating system and type of $h^{2}$ estimate and this led us to use only random mating in later experiments. The age effect is very highly significant and there is no interaction of age and type of $h^{2}$ estimate. We may therefore reasonably conclude that the age mediated difference in $h^{2}$ between "old" and "young" families is real. However, it could be argued that, as the cultures for the two sets were grown under different conditions, the difference could have arisen from some systematic environmental difference between the two sets of cultures. In order to eliminate this possibility in subsequent experiments, all cultures in the later tests were grown concurrently, with different parents producing the 
TABLE 2

\begin{tabular}{lccccc}
\multicolumn{7}{c}{ Analysis of variance of estimates of $\mathbf{h}^{2}$ in table 1} \\
\multicolumn{1}{c}{ Item } & $\mathrm{S}^{2}$ & d.f. & m.s. & F & P \\
Mating system & 0.038329 & 1 & 0.038329 & 13.60 & $<0.01$ \\
Emergence period & 0.039994 & 2 & 0.019997 & 7.10 & $<0.001$ \\
Type of $h^{2}$ estimate & 0.382033 & 1 & 0.382033 & 135.57 & $<<0.001$ \\
Age of parent & 0.085921 & 1 & 0.085921 & 30.49 & $<0.001$ \\
Mating $\times$ type $h^{2}$ & 0.019291 & 1 & 0.019291 & 6.84 & $<0.05$ \\
Mating $\times$ emergence & 0.065463 & 2 & 0.032731 & 11.61 & $<0.01$ \\
Mating $\times$ age & 0.045838 & 1 & 0.045838 & 16.27 & $<0.02$ \\
Emergence $\times$ type $h^{2}$ & 0.042006 & 2 & 0.021003 & 7.45 & $<0.02$ \\
Emergence $\times$ age & 0.005250 & 2 & 0.002625 & 0.93 & $>0.5$ \\
Type $h^{2} \times$ age & 0.001175 & 1 & 0.001175 & 0.32 & $>0.5$ \\
Error & 0.025360 & 9 & 0.002818 & - & - \\
& - & & & &
\end{tabular}

"old " and the "young" progenies. The second experiment also tested the influence of the following variables:

\section{Relative effects of parental age in the two sexes}

Three-day and 28-day-old flies were mated in all possible combinations.

\section{Age at mating of females and males}

Some 28-day-old flies of both sexes were mated at 3 days of age. Others were kept until they were 26 days old before being mated.

\section{Effects of stored sperm in females}

Some 28-day females inseminated when young were " deseminated " by a freezing technique and their performance was compared with similar virgin females and untreated oviparous females.

Table 3 gives the values for the OP $h^{2}$ estimates obtained, and permits some useful comparisons to be made. Both $\mathrm{A}$ and $\mathrm{B}$ estimates, using old females, are highly significantly greater than the $\mathrm{G}$ estimates for young parents. However, it would not be correct to conclude from the similarity of the A and B estimates that the age of the male is unimportant. Estimates $\mathrm{I}$ and $\mathrm{D}$ for young females mated to old males are not significantly different from each other, indicating that the virginity of the male is probably of no consequence. If these two estimates are pooled, a combined estimate of $0 \cdot 434 \pm 0.048$ is obtained and when this is compared with the $\mathrm{G}$ estimate for young females mated to young males a $\mathrm{P}$ value of $<0.002$ is obtained. This indicates that, when young females are used as mothers, paternal age does influence heritability of bristle number, though it seems unlikely that there is a male age effect when the females used are old. (Compare A with B, F with E, E with C.)

The close similarity of estimates $\mathrm{E}$ and $\mathrm{F}$ and of $\mathrm{E}$ and $\mathrm{G}$ must be taken to mean that the freezing treatment, used effectively to kill old sperm within females (Lefevre and Ulla-Britt, 1962), does not influence heritability and likewise that the presence of old sperm remaining in the female for a lengthy period has no direct detectable effect upon estimates of $h^{2}$ made with old females. Old sperm might well, however, have an indirect effect operating through the female system at an earlier period.

The $h^{2}$ estimates E, F, G and $\mathrm{H}$ do not differ significantly from one 
another and A and B are likewise similar. Comparisons of these two groups show that the combined estimate based on $A+B(0.575 \pm 0.056)$ is significantly higher $(\mathrm{P}=<0.01)$ than that based upon $\mathrm{E}+\mathrm{F}+\mathrm{G}+\mathrm{H}(0.39 \pm$ $0.034)$. This must be taken to mean that the age at mating of females has an effect upon heritability. We have noted as a general feature of these experiments that $h^{2}$ estimates based on females first mated when old are generally higher than those derived from old females first mated when young. Whether this effect is caused by the initial mating or by sperm-promoting changes in the inseminated females after copulation is not yet established.

TABle 3

Estimates of $O P \mathrm{~h}^{2}$ of SPC for parents of different ages at time of mating and significance of differences between parents aged 3 days and older parents. Experiment $I I .(F)=$ cold treatment to kill sperm

\begin{tabular}{|c|c|c|c|c|c|}
\hline Block & $\begin{array}{l}\text { Age of } \\
\text { females } \\
\text { (days) }\end{array}$ & $\begin{array}{l}\text { Age of } \\
\text { males } \\
\text { (days) }\end{array}$ & $h^{2}$ & $\begin{array}{c}\text { Mean } \\
\text { within } \\
\text { culture } \sigma^{2}\end{array}$ & $\begin{array}{l}\text { No. of } \\
\text { cultures }\end{array}$ \\
\hline A & 28 & 3 & $\begin{array}{l}0.594 * * * * \\
( \pm 0.079)\end{array}$ & $2 \cdot 756$ & 76 \\
\hline B & 28 & 28 & $\begin{array}{l}0 \cdot 562 * * * \\
( \pm 0 \cdot 085)\end{array}$ & 3.018 & 76 \\
\hline C & 3 & 3 & $\begin{array}{l}0.226 \\
( \pm 0 \cdot 072)\end{array}$ & $3 \cdot 125$ & 78 \\
\hline D & 3 & 28 & $\begin{array}{l}0.400 * \\
( \pm 0.066)\end{array}$ & $2 \cdot 842$ & 80 \\
\hline $\mathbf{E}$ & $28 \dagger(F)$ & 3 & $\begin{array}{l}0.473 * * \\
( \pm 0.060)\end{array}$ & $2 \cdot 831$ & 80 \\
\hline $\mathbf{F}$ & $28 \dagger(F)$ & 28 & $\begin{array}{l}0.340^{\circ} \\
( \pm 0.067)\end{array}$ & $2 \cdot 814$ & 80 \\
\hline G & $28 \dagger$ & 3 & $\begin{array}{l}0.424^{*} \\
( \pm 0 \cdot 077)\end{array}$ & $3 \cdot 233$ & 68 \\
\hline $\mathbf{H}$ & $28 \dagger$ & 28 & $\begin{array}{l}0.338^{\circ} \\
( \pm 0.071)\end{array}$ & $3 \cdot 180$ & 78 \\
\hline I & 3 & $28 \dagger$ & $\begin{array}{l}0 \cdot 471 * * * \\
( \pm 0 \cdot 070)\end{array}$ & $2 \cdot 657$ & 74 \\
\hline $\mathrm{J}$ & 28 & $28 \dagger$ & $\begin{array}{l}0.212^{\circ} \\
( \pm 0.070)\end{array}$ & $3 \cdot 106$ & 80 \\
\hline
\end{tabular}

The only obviously inconsistent feature of table 3 is the very low value of $h^{2}$ for block J. Unfortunately this value is not strictly comparable with those for other blocks as the progenies were counted some eight days later because of illness. Considerable mortality of about 50 per cent occurred in the progenies of block $\mathrm{J}$ during this period of time, and although an attempt to minimise possible biasing effects of selective death was made by including dead flies in the sample counted, many flies (often approximately half of the dead individuals) were excluded because they were partly or wholly covered by the medium. In consequence, this estimate must be regarded with some reserve until new estimates are available.

In experiments III and IV we attempted to follow changes in $h^{2}$ over a longer period and at shorter intervals. Both experiments were carried out in the same way and the estimates obtained (table 4) from parents of the same age in the two experiments are not significantly different from one another in any case ( $P$ values between 0.9 and $0 \cdot 1$ ).

From the data in table 4 it is clear that there is a large change in the 
value of OP $h^{2}$ between 3 and 14 days with, thereafter, little variation. The HS estimates are slightly different but have the same general appearance. Comparison of the combined estimates of OP $h^{2}$ shows that the 14-, 28- and 42-day estimates based on combined samples are significantly higher than the 3-day estimate. 56- and 70-day estimates are not significantly different from the 3-day value, but this may be more a consequence of sample size than a reflection of a real decline in the value of $h^{2}$ in the later weeks.

TABLE 4

Estimates of $\mathrm{h}^{2}$ of SPC for parents of different ages and the significance of differences between $\mathrm{h}^{2}$ estimates based on parents aged 3 days and older parents. Experiments III and IV

\begin{tabular}{|c|c|c|c|c|c|c|c|}
\hline \multirow{2}{*}{$\begin{array}{l}\text { Age of } \\
\text { parents }\end{array}$} & \multicolumn{2}{|c|}{ OP $h^{2}$} & \multirow{2}{*}{$\begin{array}{c}\text { OP } h^{2} \\
\text { Combined } \\
\text { III + IV }\end{array}$} & \multicolumn{2}{|c|}{$\mathrm{HS} h^{2}$} & \multicolumn{2}{|c|}{$\begin{array}{l}\text { No. of } \\
\text { cultures }\end{array}$} \\
\hline & III & IV & & III & IV & III & IV \\
\hline 3 & 0.264 & 0.286 & $\begin{array}{l}0.279 \\
( \pm 0.081)\end{array}$ & 0.348 & 0.365 & 64 & 60 \\
\hline 14 & 0.478 & 0.488 & $\begin{array}{l}0.485^{*} \\
( \pm 0.062)\end{array}$ & 0.401 & 0.546 & 64 & 60 \\
\hline 28 & $\begin{array}{l}0.442 \\
0.473 \dagger\end{array}$ & 0.488 & $\begin{array}{l}0.522 * * \\
( \pm 0.048)\end{array}$ & $\begin{array}{l}0.431 \\
0.563 \dagger\end{array}$ & 0.446 & $\begin{array}{l}64 \\
64\end{array}$ & $\frac{60}{-}$ \\
\hline 42 & 0.573 & 0.334 & $\begin{array}{l}0.518 * \\
( \pm 0.08)\end{array}$ & 0.531 & 0.523 & 64 & 60 \\
\hline 56 & - & 0.429 & $\begin{array}{l}0.429^{\circ} \\
( \pm 0.105)\end{array}$ & - & 0.474 & - & 60 \\
\hline 70 & - & 0.479 & $\begin{array}{l}0.479^{\circ} \\
( \pm 0 \cdot 111)\end{array}$ & - & 0.344 & - & 36 \\
\hline
\end{tabular}

\section{Discussion}

Estimates of heritability depend upon measurement of the resemblance between relatives. In the case of offspring-mid-parent comparisons, they depend upon estimates of the parent-offspring covariance based on the calculation of parent-offspring regression. The parent-offspring relation is generally measured at any convenient point in the parental life-cycle. The justification for this rests on the assumption that, on average, the successive progenies of ageing parents are genetically identical. Even if they are genetically identical the confident use of $h^{2}$ values in breeding and selection programmes still rests on various other assumptions. The first of these is that the genotypic values of both homozygotes and heterozygotes remain constant, i.e. that the intra-allelic additivity and the degree of dominance remain constant. Secondly, that only small-and constant-fractions of the interaction variance arising from epistasis contribute to the covariance and that therefore the effect of it on the resemblance between relatives is small. Furthermore, in the estimation of heritability from the parent offspring regression it is assumed that the environmental covariance, or more precisely various sources of common environmental variation, do not contribute appreciably to the resemblance between parent and offspring. Finally, it is supposed that the various sources of common environmental variance, for instance, that of the positional information provided by ovulae produced at different ages by identical females remain constant, i.e. that gene-environment reactions are in that respect negligible. 
From our data it follows that one or more of these assumptions must be questioned for it is clear that heritability of sternopleural chaeta number increases with the age of the parents. So far as our results go, they indicate that the increase takes place by 14 days of age. However, it is possible that the heritability-parental age relationship is not a simple directional effect. Indeed, data on age $/ h^{2}$ effects using abdominal chaeta number (Lints, unpublished) suggest that there are cyclic variations in the value of $h^{2}$ with age and that this is most marked when age is measured as relative age rather than absolute age. Relative age at any point in time is defined as the ratio of age at that point to total life-span of the individual and hence requires the measurement of individual life spans. In this study no systematic counts of life-span have been made.

The data reported here, however, are not inconsistent with the view that there is a variation in $h^{2}$ with increase in relative age. In particular, the observation that females mated at 2 days give significantly lower values of $h^{2}$ when tested at 28 days of age than otherwise similar females kept as virgins until 26 days of age and tested as 28-day parents is relevant. As females which are laying eggs have a shorter average life-span than virgin females (Bilewicz, 1953), clearly the relative ages of these two types of female must be different at the same absolute age.

However, for the moment it seems safest merely to conclude that there is a difference between younger and older parents and that from the age of 14 days little change takes place.

A summary of the random mating $h^{2}$ estimates obtained in these four experiments is set out in table 5. A Wilcoxon rank test comparing $h^{2}$ values

TABLE 5

Summary of estimates of $\mathrm{h}^{2}$ of SPC obtained from randomly mated parents of different ages in four experiments. (The letters by the 28-day) estimates in experiment II refer to the blocks in table 3)

\begin{tabular}{|c|c|c|c|c|}
\hline \multirow[b]{2}{*}{ Experiment } & \multicolumn{4}{|c|}{ Age of parents (days) } \\
\hline & 3 & 14 & 21 & 28 \\
\hline 1 & $\begin{array}{l}0.261 \\
0.292 \\
0.358\end{array}$ & $\underline{-}$ & $\begin{array}{l}0.310 \\
0.391 \\
0.456\end{array}$ & $\overline{-}$ \\
\hline II & $0 \cdot 226$ & - & - & $\begin{array}{l}0.562(\mathrm{~B}) \\
0.340(\mathrm{~F}) \\
0.338(\mathrm{H}) \\
0.212(\mathrm{~K})\end{array}$ \\
\hline III & $0 \cdot 264$ & $0 \cdot 478$ & - & $\begin{array}{l}0.442 \\
0.473\end{array}$ \\
\hline IV & 0.286 & 0.488 & - & 0.488 \\
\hline
\end{tabular}

in this table for 3-day and older parents gives a $T$ value of 30 with $P=0.01$ for the two groups being drawn from the same population. The evidence for an age effect on OP $h^{2}$ is thus consistent and strong, though it is clearly necessary to assay $h^{2}$ with parents having ages between 3 and 14 days to determine the nature of the effect in more detail.

A summary of the HS $h^{2}$ values corresponding to the OP values in table 5 is given in table 6 . The value of the Wilcoxon $T$ in this case is 25 and the 
attached probability is again less than $0 \cdot 01$. Thus the HS figures broadly support the conclusions derived from the OP estimates although the effect is probably less clear cut than with OP values.

TABLE 6

Summary of HS estimates of $\mathrm{h}^{2}$ of SPC obtained from randomly mated parents of different ages in four experiments. (The letters by the 28-day estimates in experiment II refer to the blocks in table 3)

\begin{tabular}{lcccc}
\multirow{2}{*}{$\begin{array}{c}\text { Experiment } \\
\text { I }\end{array}$} & 0.403 & -14 & 21 & 28 \\
& 0.443 & - & 0.650 & - \\
II & 0.540 & - & 0.607 & - \\
& 0.336 & - & - & $0.519(\mathrm{~B})$ \\
& & & & $0.378(\mathrm{~F})$ \\
III & 0.348 & 0.401 & - & $0.483(\mathrm{H})$ \\
& & & & $0.549(\mathrm{~K})$ \\
IV & 0.365 & 0.546 & & 0.531 \\
& & & & 0.446
\end{tabular}

Some pertinent data also are available from the work of Mr S. Shami who is investigating fin ray number heritability in Poecilia in Swansea. He finds that there is a significant linear increase of $h^{2}$ for this character for parents between 4.5 and 10.5 months of age with a plateau thereafter. This suggests that the effect observed in Drosophila is not peculiar to this organism and that possibly a plateau is reached in Drosophila by 14 days of age.

$A$ priori it might be supposed that if heritability were to change with age it would be more likely to decrease than to increase. This is because it has been argued that there is an accumulation of mutational, translational or transcriptional errors (all of which can be regarded as quasi-mutational) with age in somatic cells (Szilard, 1959; Orgel, 1963; Curtis, 1971). Although the argument has not been extended to cells undergoing meiosis to form gametes, it seems reasonable to suppose that if such accumulation does occur it will be found in these cells too.* Under these conditions, the resemblance between parent and offspring for a phenotypic character with a value fixed at a point early in life (as with bristle number) should diminish with age. Our results show that if such accumulation occurs it is more than compensated for by other processes which act to increase this resemblance as parents age.

The observed increase in $h^{2}$ with parental age could be due to a decrease in the amount of recombination in parental flies. This is because the total phenotypic variance of individual cultures of outbred material would be expected to decrease with reduced recombination. Hence the variance of progeny means will also be reduced. This in turn will lead to an increase in the covariance term used in calculating $h^{2}$ and a higher value of the latter. However, the existence of a " male " effect suggests that reduced recombination, even if it applies, cannot be the whole of the story, as there is no recombination in the male Drosophila. Furthermore, the mean phenotypic

* Note added in proof. However, this argument does seem implicit in Sir Mcfarlane Burnet 1974, Intrinsic Mutagenesis a genetic approach to ageing. M. J. P. Lancaster. 
variance within progenies does not show a decrease with age. In fact, as table 3 shows, the mean within-progeny variance for SPG shows no consistent variation with variation in $h^{2}$. This must tend to discount any systematic effect of age upon recombination although a variety of age effects upon recombination in particular regions of the Drosophila genome have been described (Bridges, 1929; Valentin, 1973) and other relevant data have been obtained by Parsons (1962).

Variation in meiotic drive of affinity should also be considered as possible causes of an age effect. However, inequalities in the products of female and male meiosis as well as some cases of differential fertilisation have always been related to major genes or gross disturbances of various kinds and are therefore not necessarily relevant to the type of characters under discussion. In any case, our present data do not permit us to examine critically variations in segregation ratio as a cause of the age effect.

Another possible explanation might lie in a change with age in the quantity of genetic material which passes into gametes. Darlington and La Cour (1941) showed that in mitosis heterochromatin may not always divide so as to pass to daughter nuclei in equal amounts. Mather and Jinks (1971) have argued that this may be of particular importance for the evolution of the genes of quantitative inheritance. It might be further supposed that age affects the replication or segregation of parts of the genome of Drosophila in such a way as to produce gametes with consistently different amounts of genetic information at different parental age; possibly by differential activity of master-slave complexes (Gallan, 1967). Such a type of inheritance involving an environmental effect upon genes is unexpected; yet it is not unique, as is shown by the work of Durrant (1962, 1972), Evans (1968) and Cullis (1973), which however involves influences of the external environment.

The age effect can also be considered in terms of gene control. As the data show, the total phenotypic variance $\left(V_{P}\right)$ of progeny from older parents is not consistently different from the corresponding value for young parents. As $V_{P}=V_{G}+V_{E}$, this could mean one of two things. First, as parents age the magnitude of the total genetic variance could increase and that of the environmental variance decrease by about the same amount and hence produce no resultant effect upon $V_{P}$. Although no estimates of $V_{E}$ are available, this rather complicated process seems unlikely. Alternatively, some or all of the individual components of $V_{G}$ could change in magnitude whilst the value of $V_{G}$ remains more or less constant. This possibility is perhaps more plausible. If it is right, it implies that the additivity of action of bristle determining loci, under some conditions, and in both males and females is increased in older flies and that this change is maintained in zygotes derived from such flies. It could, of course, be that additivity does not change as such in adult flies but that information relating to genetic control systems which such flies transmit to their offspring varies with age. In this connection we may note that it has been postulated that diseases such as scrapie and kuru which are, in one sense, hereditary but also probably both genotype and time dependent may arise from changes in control systems rather than in DNA (Pattison and Jones, 1968; Whitehouse, 1973).

Experiments to assay DNA content and gene activity will obviously be needed to test whether the possible mechanisms for an age effect set out above apply. 
It is also necessary to examine the heritability of age effects in successive generations reproduced from parents of different ages and this too may provide data by which these tentative hypotheses may be critically examined. The work of Elens and others (Elens et al., 1966; Elens, 1972) in selecting for behavioural characters in mice and Drosophila, and evidence provided by an experiment of selection for abdominal bristle number which is in progress in Louvain, suggest that age effects upon heritability are long lasting and capable of being exploited by selection.

Finally, we intend to look for evidence of such age effects upon other appropriate characters in other suitable species, as it is important to establish the generality of the effect described in this paper.

\section{REFERENCES}

BEARDMORE, J. A., AND LEVINE, L. 1963. Fitness and environmental variation. 1. A study of some polymorphic populations of $D$. pseudoobscura. Evolution, 17, 121-129.

BILEWICZ, s. 1953. Experiments on the effect of reproductive functions on the length of life in Drosophila melanogaster. Folia Biologica, 1, 177-194.

BRIDGES, C. B. 1915. A linkage variation in Drosophila. F. exp. Zool., 19, 1-21.

BRIDGES, c. B. 1927. The relation of the age of the female to crossing-over in the third chromosome of Drosophila melanogaster. F. gen. Physiol., 8, 689-700.

BRIDGES, C. B. 1929. Variation in crossing-over in relation to age of female in Drosophila melanogaster. Carn. Inst. Wash. Pub., 399, 63-89.

Callan, H. G. 1967. On the organisation of genetic units in chromosomes. F. Cell Sci., 2, $1-7$.

CLAYTON, G. A., MORRIS, J. A., AND ROBERTSON, A. 1957. An experimental check on quantitative genetical theory. I. Short-term response to selection. F. Genetics, 55, 131-151.

CULLIs, c. A. 1973. DNA differences between flax genotypes. Nature, 243, 515-516.

CURTIS, H. J. 1971. Genetic factors in ageing. Adv. in Genetics, 16, 305-324.

DARLINGton, c. D., AND LA Cour, L. F. 1941. The detection of inert genes. F. Heredity, 32, $115-121$.

DURRANT, A. 1962. The environmental induction of heritable change in Linum. Heredity, $17,27-61$.

DURRANT, A. 1972. Studies on reversion of induced plant weight changes in flax by outcrossing. Heredity, 29, 71-81.

elens, A. A. 1972. Parental age and efficiency of selection for phototactism. Drosophila Information Service, 49, 71-72.

ELENS, A. A., MOURAVIEFF, A. N., AND HEUTS, M. J. 1966. The age of reproduction as a factor of transmissible divergence in learning ability in the mouse. Experientia, 22, 186-187.

EVANs, G. M. 1968. Nuclear changes in flax. Heredity, 23, 25-38.

FALCONER, D. s. 1960. Introduction to Quantitative Genetics. Oliver \& Boyd, Edinburgh and London.

FRANKHAM, R., JONES, L. P., AND BARKER, J. S. F. 1968. The effects of population size and selection intensity in selection for a quantitative character in Drosophila. I. Short-term response to selection. Genet. Res. Camb., 12, 237-248.

HEUTs, M. J. 1956. Nieuwe problematiek in de Genetica. Agricultura, 4, 343-352.

HEUTS, M. J. 1961. Effects cumulatifs de l'age parental chez la drosophile et leur explication chromosomique. Rapp. Inst. Interuniv. Sci. Nucl., 12, 3-17.

HIRAIZUMI, Y., AND WATANABE, s. 1969. Ageing effect on the phenomenon of segregation distortion in Drosophila melanogaster. Genetics, 63, 121-131.

JONES, L. P., FRANKHAM, R., AND SHERIDAN, A. K. 1969. Correlation between bristle systems in Drosophila melanogaster. Aust. F. biol. Sci., 22, 1473-1484.

KisLovsky, D. A. 1937. Bull. Acad. Sci. U.R.S.S. (Sci. math. nat.), 121-173 (cited by Lerner, 1958).

LEFEVRE, G. JNR, AND ULLA-BRITT, J. 1962. The effects of cold shock on Drosophila melanogaster sperm. Drosophila Information Service, 36, 86-87.

LERNER, I. M. 1954. Genetic Homeostasis. Oliver \& Boyd, Edinburgh.

LERner, I. M. 1958. The Genetic Basis of Selection. John Wiley \& Sons, Ins., New York.

$34 / 1-\mathbf{F}$ 
LEWIS, W. L., AND WARWICK, E. J. 1953. Effectiveness of selection for body weight in mice from inbred and outbred populations derived from common parent stocks. F. Hered., $44,233-238$.

LINTs, F. A. 1961. Diversity by inbreeding in Drosophila. Genetica, 32, 177-199.

LUSH, J. L. 1941. Methods of measuring the heritability of individual differences among farm animals. Suppl. Vol. of J. Genetics, p. 199.

mather, K., AND Jinks, J. L. 1971. Biometrical Genetics. Chapman \& Hall, London. MEDvedev, zH. A. 1967. Molecular aspects of ageing. Symp. Soc. Exp. Biol., 21, 1-28.

ORGEL, L. E. 1963. The maintenance of the accuracy of protein synthesis and its relevance to ageing. Proc. Nat. Acad. Sci., U.S.A., 49, 517-521.

PARsons, P. A. 1962. Maternal age and developmental variability. 7. exp. Biol., 39, 251260.

Parsons, P. A. 1964. Parental age and the offspring. Quart. Rev. Biol., 39, 258-275.

PATTison, I. H., AND JoNks, K. M. 1968. Detection of the scrapie agent in tissues of normal mice and in tumours of tumour-bearing but otherwise normal mice. Nature, 218, 102104.

PENROSE, L. 1965. Mongolism as a Problem in Human Biology in the Early Conceptus, Normal and Abnormal, ed. W. W. Park and D. C. Thomson.

PETIT, c. 1963. L'influence du mode de croisement sur la structure genetique des populations: la stabilite des populations experimentales de faible effectif. Ann. Génétique, 6, 29-35.

PLOUGH, н. H. 1917. The effect of temperature on crossing-over in Drosophila. F. exptl Zool., $24,147-209$.

POWELL, J. R. 1971. Genetic polymorphism in varied environments. Science, 174, 10351036.

RASMUSON, M. 1952. Variation in bristle number of Drosophila melanogaster. Acta Zool., 33, 277-307.

REEVE, E. C. R., AND ROBERTSON, F. W. 1954. Studies in quantitative inheritance. IV. Sternite chaeta number in Drosophila: a metameric quantitative character. Zeits. indukt. Abstamm. und Vererbungsl., 86, 269-288.

ROBERTSON, F. w. 1960. The ecological genetics of growth in Drosophila. 2. Selection for large body size on different diets. Genet. Res. Camb., 1, 305-318.

SHELDON, B. L. 1963. Studies in artificial selection of quantitative characters. 1. Selection for abdominal bristles in Drosophila melanogaster. Aust. F. biol. Sci., 16, 490-515.

szilard, L. 1959. On the nature of the ageing process. Proc. Nat. Acad. Sci., U.S.A., 45, $30-45$.

TANEJA, G. C., AND NEGI, s. 1964. Interaction between genotype and temperature for wing length, bristle number and egg-count in Drosophila ananassae. J. Genetics, 59, 19-28.

TANTAWY, A. O., MALlah, G. S., AND TEWFiK, H. R. 1964. Studies on natural populations of Drosophila. II. Heritability and response to selection for wing length in Drosophila melanogaster and Drosophila simulans at different temperatures. Genetics, 49, 935-948.

TANTAWY, A. O., AND REEVE, E. C. R. 1956. Studies in quantitative inheritance. IX. The effects of inbreeding at different rates in Drosophila melanogaster. Zeits. indukt. Abstamm. und Vererbungsl., 87, 648-667.

TOKUNAGA, c. 1970. The effects of low temperature and ageing on nondisjunction in Drosophila. Genetics, 65, 75-94.

VAlentin, H. J. 1973. Selection for altered recombination frequency. Hereditas, 74, 295-297.

WHITEHouse, н. L. к. 1973. Towards an Understanding of the Mechanism of Heredity, 3rd edition. Edward Arnold, London. 